\title{
Experimental Study on High Speed Grinding with Single Grit on Tooth Surface of 20CrMnTi Steel
}

\author{
Long Wang ${ }^{1}$, Xinli Tian ${ }^{1}$, Qian Liu ${ }^{1}$, Heng Gao ${ }^{2}$, Yang Zhang ${ }^{3}$, Penghui Yan ${ }^{4}$ \\ ${ }^{1}$ National Defense Key Laboratory for Remanufacturing Technology, Academy of Armored Forces \\ Engineering, Beijing 100072, China \\ ${ }^{2}$ Nanjing Artillery Academy, Nanjing 210000, China \\ ${ }^{3}$ military deputy office of PLA in 674 factory, Harbin, 150056 \\ ${ }^{4}$ Technological Research Institue, Shanxi Fashite Gear Co Ltd, Xi'an 710119, China \\ waloxs@163.com
}

Keywords: 20CrMnTi steel; Single grit; Scratch test; Grinding mechanism

\begin{abstract}
The grits in the surface of grinding wheel is usually high-speed curve movement in the grinding process. It constructs the test system that a single diamond grit scratching the surface of 20CrMnTi steel under the high-speed curve movement. The research shows that there are obvious plastic bulge on both sides of the scratch, and the strengthening trace with plastic deformation at the bottom of the groove. With the increase of grinding speed, grinding force first increases and then decreases. Grinding force increases with the increase of grinding depth and feed speed.
\end{abstract}

\section{Introduction}

Generating grinding gear by worm wheel and form grinding gear is the mainstream technology to finish the 20CrMnTi carburized steel gear. The grinding process of the work piece material is essentially a cumulative effect of a large number of abrasive grains on the micro-cutting action of the material, and a plurality of microscopic grinding marks are formed on the work piece grinding surface. Many scholars at home and abroad mostly use a single abrasive grain scratch test to simulate the grinding process instead of the whole wheel grinding test, it is to provide a very important reference value about carrying out grinding mechanism research. However, the straight line rubbing study of single grain cannot explain the cutting behavior which the single abrasive grains on the grinding wheel in the actual tooth surface grinding process remove the material under the high speed curve movement. Actually, the wheel often has a fast tangential velocity when it is near or away from the tooth surface in the grinding process. In order to facilitate studying this problem, the author simplified the abrasive grain into conical geometry, and the Single corundum abrasive grain was used in the high-speed curve movement under 20CrMnTi steel surface scratching test. It was not only to make that the scratching behavior by a single abrasive grain was closer to the cutting behavior of abrasive on the wheel surface in the actual grinding process grinding, but also beneficial to study the basic law of grinding force and the material removal mechanism.

\section{Scratch Test System and Method}

The scratch test system was shown in Fig. 1 that it was experimented on the plane of 20CrMnTi steel by the use of diamond abrasive grain in the condition of non-lubricating. Four conical single diamonds with particle size of $46^{\#}$ were brazed to the 45 steel discs with a diameter of $150 \mathrm{~mm}$ and a thickness of $5 \mathrm{~mm}$. The scratch test used 20CrMnTi carburized hardened steel work piece with the size of $100 \mathrm{~mm} \times 30 \mathrm{~mm} \times 3 \mathrm{~mm}$ and the surface hardness of 58-62 HRC. The density of 20CrMnTi steel is $7800 \mathrm{~kg} / \mathrm{m} 3$, the elastic modulus is $207 \mathrm{GPa}$ and the Poisson ratio is 0.25 . The diamond abrasive was fixed on the spindle controller of FANUC BV75 vertical machining center to ensure that the diamond tip scratched the surface of 20CrMnTi steel work piece. Switzerland KISTLER 94272 models of high-performance strain gauge milling and drilling mill universal dynamometer 
were used for the force measurement. Nova Nano SEM 450 environmental scanning electron microscope was employed to observed the microscopic morphology of scratch marks.

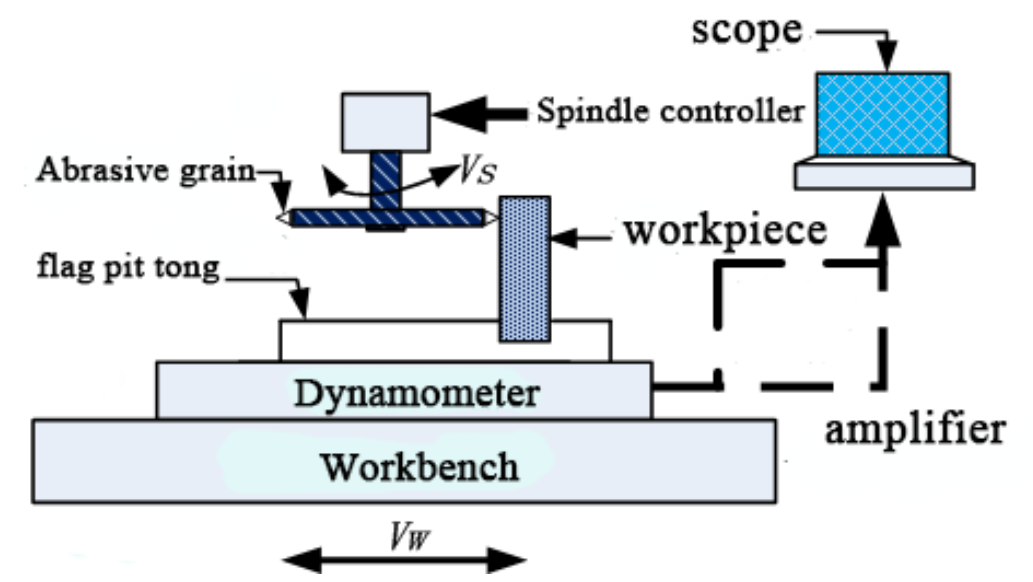

Figure 1. Single grain abrasive high-speed scratch test system

\section{Result and Analysis}

Scratch Morphology Analysis. Fig. 2 is the scratches microscopic morphology by grinding 20CrMnTi with a single diamond abrasive under high speed curve movement. The Fig. 2 shows that the trench on either side of the plastic bulge was forming, plastic deformation strengthening traces for groove at the bottom of the material. When grinding grain of cutting-edge interference in depth of the contact materials began to rapidly increase, the abrasive grain and workpiece material after the extrusion effect to enhance each other. Cutting edge began to start into the workpiece, the grinding grain and material contact area to form local elastic-plastic degeneration area. With grinding grain on the workpiece moving, dislocation slip in the crystal structure, material on the abrasive front and sides uplift, workpiece surface is to draw a trench, grindings rake surface of sliding along the grits and out, and on both sides of the trench plastic bulge forming.

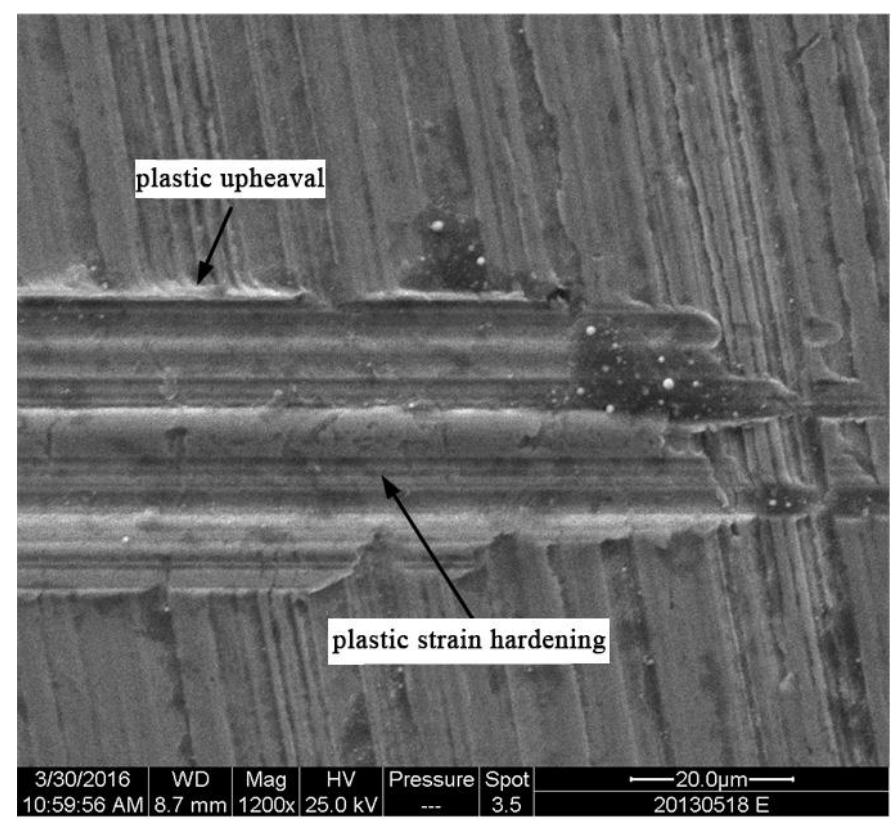

Figure 2.microscopic morphology

Grinding Force Analysis. Orthogonal test is a kind of multi-factor optimization experiment design method, experimental number after can use relatively less likely to a reasonable conclusion. As shown in table 1, by arranging for 16 different set under the condition of the orthogonal 
experiment, the experiment in each group to maximize stroke wiped in the process of grinding force as a constant.

Table 1.Orthogonal test conditions and results

\begin{tabular}{ccccc}
\hline $\begin{array}{c}\text { Grinding } \\
\text { speedm/s }\end{array}$ & $\begin{array}{c}\text { Grinding } \\
\text { depth/mm }\end{array}$ & $\begin{array}{c}\text { Feed speed } \\
\mathrm{mm} / \mathrm{s}\end{array}$ & $\begin{array}{c}\text { Normal } \\
\text { force/N }\end{array}$ & $\begin{array}{c}\text { Tangential } \\
\text { force/N }\end{array}$ \\
\hline 10 & 0.005 & 2 & 1.6 & 0.8 \\
10 & 0.01 & 3 & 2.6 & 1.5 \\
10 & 0.015 & 4 & 5 & 3 \\
10 & 0.02 & 5 & 15 & 10.2 \\
20 & 0.005 & 3 & 3.5 & 1.8 \\
20 & 0.01 & 2 & 8.6 & 4.6 \\
20 & 0.015 & 5 & 10 & 5.6 \\
20 & 0.02 & 4 & 15 & 9 \\
25 & 0.005 & 4 & 3 & 1.2 \\
25 & 0.01 & 5 & 7.6 & 3.5 \\
25 & 0.015 & 2 & 9.3 & 5 \\
25 & 0.02 & 3 & 12.9 & 7.6 \\
30 & 0.005 & 5 & 2.8 & 1 \\
30 & 0.01 & 4 & 6 & 2.5 \\
30 & 0.015 & 3 & 5.8 & 3 \\
30 & 0.02 & 2 & 6.5 & 3.8 \\
\hline
\end{tabular}

Table 2 and Table 3 are the table of the intuitive analysis and analysis of variance about the normal force and tangential force. The influence order of rubbing factors amount on grinding force can be known through the analysis of range and variance ratio F.The the average value of the difference of the three factors-Grinding speed, grinding depth and feed speed in the level of the average normal force were 4.005, 9.63,2.645, and the variance ratio were 0.499,2.299,0.202. Similarly The difference of tangential force were $2.675,6.45,1.6$, the variance ratio of tangerntial force were $0.405,2.416,0.179$.In summary, grinding depth, grinding speed, feed rate on the normal grinding force and tangential grinding force were weakened in turn.

Table 2. Intuitive analysis and analysis of variance of normal force

\begin{tabular}{cccc}
\hline & $\begin{array}{c}\text { Grinding } \\
\text { speed(m/s) }\end{array}$ & $\begin{array}{c}\text { Grinding } \\
\text { depth }(\mathrm{mm})\end{array}$ & $\begin{array}{c}\text { Feed } \\
\text { Speed }(\mathrm{mm} / \mathrm{s})\end{array}$ \\
\hline average 1 & 6.05 & 2.72 & 6.5 \\
average 2 & 9.275 & 6.2 & 6.2 \\
average 3 & 8.2 & 7.525 & 7.25 \\
average 4 & 5.27 & 12.35 & 8.845 \\
difference & 4.005 & 9.63 & 2.645 \\
Deviation sum & 41.412 & 190.794 & 16.794 \\
of squares & & & \\
F radio & 0.499 & 2.299 & 0.202 \\
\hline
\end{tabular}


Table 3. Intuitive analysis and analysis of variance of tangential force

\begin{tabular}{cccc}
\hline & $\begin{array}{c}\text { Grinding } \\
\text { speed(m/s) }\end{array}$ & $\begin{array}{c}\text { Grinding } \\
\text { depth(mm) }\end{array}$ & $\begin{array}{c}\text { Feed } \\
\text { Speed }(\mathrm{mm} / \mathrm{s})\end{array}$ \\
\hline average 1 & 3.875 & 1.2 & 3.55 \\
average 2 & 5.25 & 3.025 & 3.475 \\
average 3 & 4.325 & 4.15 & 3.925 \\
average 4 & 2.575 & 7.65 & 5.075 \\
difference & 2.675 & 6.45 & 1.6 \\
Deviation sum & & & 6.557 \\
of squares & 14.857 & 88.542 & \\
F radio & 0.405 & 2.416 & 0.179 \\
\hline
\end{tabular}

This section respectively took the different levels of grinding parameters as the abscissa axis, and corresponding to different levels of the average normal force and the average tangential force as the vertical axis in Table 2 and Table 3 to draw the Relationship of grinding factors between the averages grinding force. As it is shown in Fig. 3. It can be seen from Fig. 3a that the normal force and tangential force of diamond grains increase firstly and then decrease after $20 \mathrm{~m} / \mathrm{s}$ as the grinding speed keeps on increasing. The reason is as follows: on the one hand, with the increase of the grinding speed, the strain-rate strengthening effect of the material being processed is stronger, which leads to the increase of the shear resistance of the material. On the other hand, as the grinding speed increases, the grinding temperature increases, and the heat softening effect causes the shear slip resistance of the material to decrease, so the grinding force tends to decrease. When the grinding speed is lower than $20 \mathrm{~m} / \mathrm{s}$, the strain rate strengthening effect is in the leading role. Fig. $3 \mathrm{~b}$ and Fig. 3c shows that the normal force and tangential force are the same as the scratch depth, the feed rate to maintain an increasing relationship. The reason is that the maximum unreformed cutting thickness of abrasive grains increases with the increase of feed rate and grinding depth, and the deformation resistance and friction force of abrasive extruded material increase.

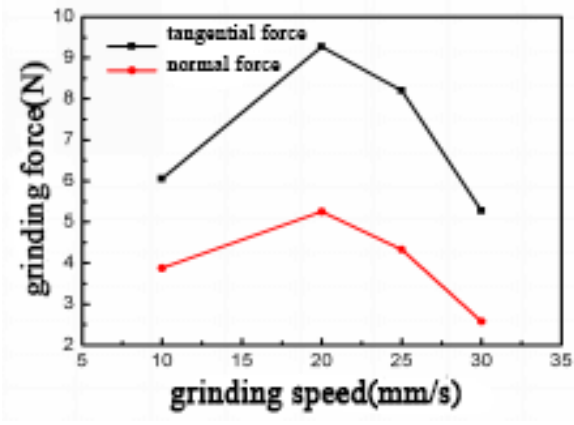

(a)grinding speed

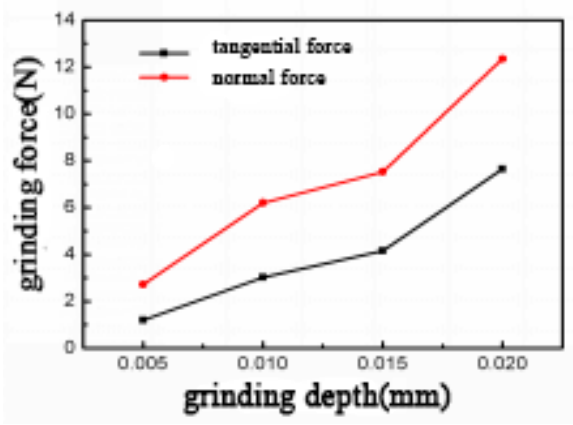

(b) grinding depth

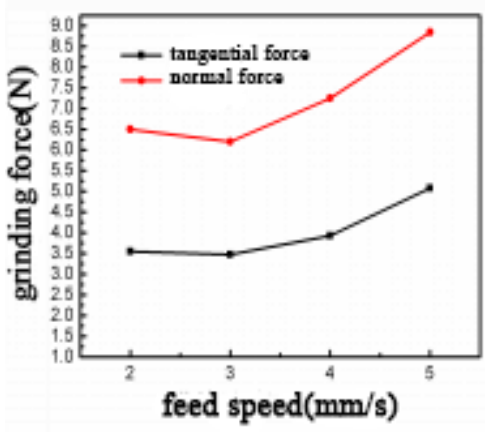

(c) feed speed

Figure 3. Average value of grinding force based on grinding factors variety 


\section{Conclusion}

SEM was used to observe the surface scratches of 20CrMnTi steel. There were significant plastic ridges on both sides of the groove, and the plastic removal process was further discussed. The effects of grinding parameters, such as grinding speed, grinding depth and feed rate, on grinding force are analyzed. Grinding depth, grinding speed and feed rate on the grinding force of the degree of weakening. As the grinding depth and feed rate increases, the unreformed chip thickness increases, resulting in increased grinding force. Increasing the grinding speed results in both strain-rates strengthening and heat-softening of the material, which, however, can have the opposite effect on the grinding force. The change in grinding force depends on the balance between strain rate strengthening and heat softening. With the increase of grinding speed, the grinding force increases first and then decreases, and the turning inflection point is about $20 \mathrm{~m} / \mathrm{s}$.

\section{Reference}

[1] G. Werner:Annals of CIRP, Vol. 27(1978) No.1,p.243-248.

[2] S.Mlakin and N.H. Cook:Annals of the JEI,Vol.93(1971) p.1120-1133.

[3] J.Y. Tang,F. Yin and X.M. Chen:Annals of the MMT,Vol. 70 (2013) p.1-15.

[4] H.F. Chen,J.Y Tang and W. Zhou:Annals of the JMPT,Vol. 213(2013) p.717-721.

[5] B.M. Li and B. Zhao:Modern Grinding Technology(China Machine Press,Beijing 2003).

[6] Y. Wang,J.H. Xu and L. Yang:Annals of the OPE,Vol. 23(2015) No.7, p.2031-2042.

[7] Z.Y. Mi and Z.Q. Liang:Annals of the OPE,Annals of the ACTA ARMAMENTARII,Vol. 36(2015) No.6, p.1067-1073.

[8] X.Z. Ren and J.P. Ding:Annals of the KEM,Vol. 464(2011) p.401-404.

[9] B.F. Feng,G.D. Cai and X.L. Sun:Annals of theKEM,Vol. 304(2006) p.401-404.

[10] Y. Ohbuchi and T. Matsuo:Annals of the CIRP,Vol. 40(1991) No.1, p.401-404. 